\title{
A Unique Way of Removing Mandibular Third Molars - Implosion Technique
}

\author{
Mohmed Isaqali Karobari ${ }^{1}$, Jawaad Ahmed Asif ${ }^{2}$, Tahir Yusuf Noorani ${ }^{3}$ \\ 1, 3 Conservative Unit, School of Dental Sciences, University Sains Malaysia, Health Campus, Kubang Kerian 16150, \\ Kelantan, Malaysia. ${ }^{2}$ Oral and Maxillofacial Surgery Unit, School of Dental Sciences, University Sains Malaysia, Health \\ Campus, Kubang Kerian 16150, Kelantan, Malaysia.
}

The average time consumed for disimpaction of mandibular third molar using rotatory instruments was approximately 17 mins and 23 mins while using a piezotome.

The authors introduce a new technique of disimpaction of mandibular third molar with the least amount of bone removal ever achieved during mandibular third molar removal. This technique can be readily included in routine clinical practice and can be performed by using routine rotary instruments. This technique was successfully accomplished in 10 individuals with the least amount of discomfort and post-operative complications reported from day 1 to day 14 .

The procedure was evaluated based on time of the procedure, pain score, bleeding, nerve injury, trismus, swelling \& dry socket.

Third molar removal has been the most frequently performed oral surgical procedure in the modern world of dentistry. ${ }^{1}$ Although, mandibular third molar is the most commonly performed procedure, it demands skill, technique and experience. Several techniques have been implied for disimpaction of mandibular third molar, but every method involves either considerable amount of bone removal or splitting the bone. Bone manipulation is done by using a rotary instruments or chisel and mallet. The most popular techniques are buccal bone guttering, distal bone removal, lingual bone split technique and lingual bone guttering. ${ }^{2}$

According to the traditional classifications of impacted mandibular third molar (Pell \& Gregory and Winter's classification), the minimum amount of bucco-distal bone removed during disimpaction of mesioangularly positioned class I A impacted mandibular third molar using rotary instruments and conventional techniques can be calculated as $157.5 \mathrm{~mm} 2$ (volume of a rectangle $=\mathrm{L} \mathrm{X} \mathrm{W} \mathrm{X} \mathrm{H}$; where $\mathrm{L}=15 \mathrm{~mm}, \mathrm{~W}$ $=1.5 \mathrm{~mm}$ [width of the bur] and $\mathrm{H}=7 \mathrm{~mm}$ ).

The mandibular third molar requiring osteotomy and tooth section have the highest risk of complications ${ }^{3}$. Surgical time had significantly increased in cases which required osteotomy and tooth section. Post-operative swelling and pain has been recorded as significant complications after using rotary instruments via buccal approach followed by use of chisel \& mallet and least in lingual split approach. On the contrary, post-operative nerve injury and trismus were significantly high in lingual split technique. Dry socket was more in patients of bur technique. ${ }^{2}$
Corresponding Author:

Dr. Jawaad Ahmed Asif

School of Dental Sciences, University Sains Malaysia, Health Campus, 16150 Kubang Kerian, Kelantan, Malaysia.

E-mail:doctorjawaad@gmail.com

DOI: $10.14260 /$ jemds/2021/162

How to Cite This Article:

Karobari MI, Asif J, Noorani TY. A unique way of removing mandibular third molars implosion technique. J Evolution Med Dent Sci 2021;10(10):752-754, DOI: 10.14260/jemds/2021/162

Submission 30-08-2020,

Peer Review 10-01-2021,

Acceptance 16-01-2021,

Published 08-03-2021.

Copyright (C) 2021 JEMDS. This is an open access article distributed under Creative Commons Attribution License [Attribution 4.0 International (CC BY 4.0)] 
The average time consumed for removal of mandibular third molar using rotatory instruments was approximately 17 mins $^{4}$ and 23 mins while using a piezotome. ${ }^{5}$

The authors introduce a new technique of disimpaction of mandibular third molar with least amount of bone removal ever achieved during mandibular third molar removal. This technique can be readily included in routine clinical practice and can be performed by using routine rotary instruments. This technique was successfully accomplished in 10 individuals with least amount of discomfort and postoperative complications reported from day 1 to day 14 . The procedure was evaluated based on time of procedure, pain score, bleeding, nerve injury, trismus, swelling \& dry socket.

The author and his team used implosion technique primly for class I and II A and class I B according to Pell \& Gregory classification. Mesioangular, vertical and horizontally impacted mandibular third molar teeth were exclusively included.

The average amount of bone removed during implosion technique was calculated to be $45 \mathrm{~mm}^{2}(\mathrm{H}=10 \mathrm{~mm}, \mathrm{~W}=1.5$ $\mathrm{mm}$ and $\mathrm{L}=3 \mathrm{~mm}$ ). The average amount of time consumed ranged from 12 - 17 mins. Pain was recorded at regular intervals over 24,48 and 72 hours using simple numeric pain scale and the maximum discomfort / pain was reported within $24 \mathrm{hrs}$. and rated as 2 on numeric pain scale. All patients were prescribed nothing more than oral paracetamol $1 \mathrm{~g}(500 \mathrm{X} 2$ tabs) as pro re nata (PRN) and not exceeding 8 tabs / day as an analgesic. 7 out of 10 patients had ceased the use of analgesic on the second post-operative day.

The steps involved are as follows-

1. Clinical and radiological assessment and planning of mandibular third molar removal (case selection) (Figure 1)

2. Local anaesthesia.

3. Standard triangular flap incision and exposing the tooth and the bone.

4. Bowdler Henry Rake Retractor used for retraction.

5. The tooth is drilled using $5 \mathrm{~mm}$ diameter stainless steel round head bur and low speed hand drill and excavated until a thin tooth wall of $<1 \mathrm{~mm}$ is left on the buccal, lingual and mesial sides (Figure 2).

6. The thickness of the buccal and lingual walls of the tooth can further be decreased using a fissure bur and low speed hand drill.

7. An approximately $1 \mathrm{~cm}$ deep and $3 \mathrm{~mm}$ long trench is drilled into the bone adjacent at mesial aspect of the tooth using $1.5 \mathrm{~mm}$ diameter round bone bur and low speed hand drill (Figure 3).

8. The newly formed bone trench is used to introduce a Coupland elevator no. 1 and break the bucco-mesial wall of the tooth to collapse it into the socket or a lower root forceps can be used to collapse all the walls. (Figure 4A).

9. The tooth debris is removed from the socket leaving only the roots in the socket.

10. An elevation point must be established at the furcation of the remaining tooth.

11. Using a curved Warwick-James elevator the remaining roots should be removed according to the curvature of the roots. (Figure 4B).

12. The bone is smoothened using bone file (if necessary).

13. The socket irrigated and tooth debris is suctioned.

14. The flap is re-approximated and sutured.
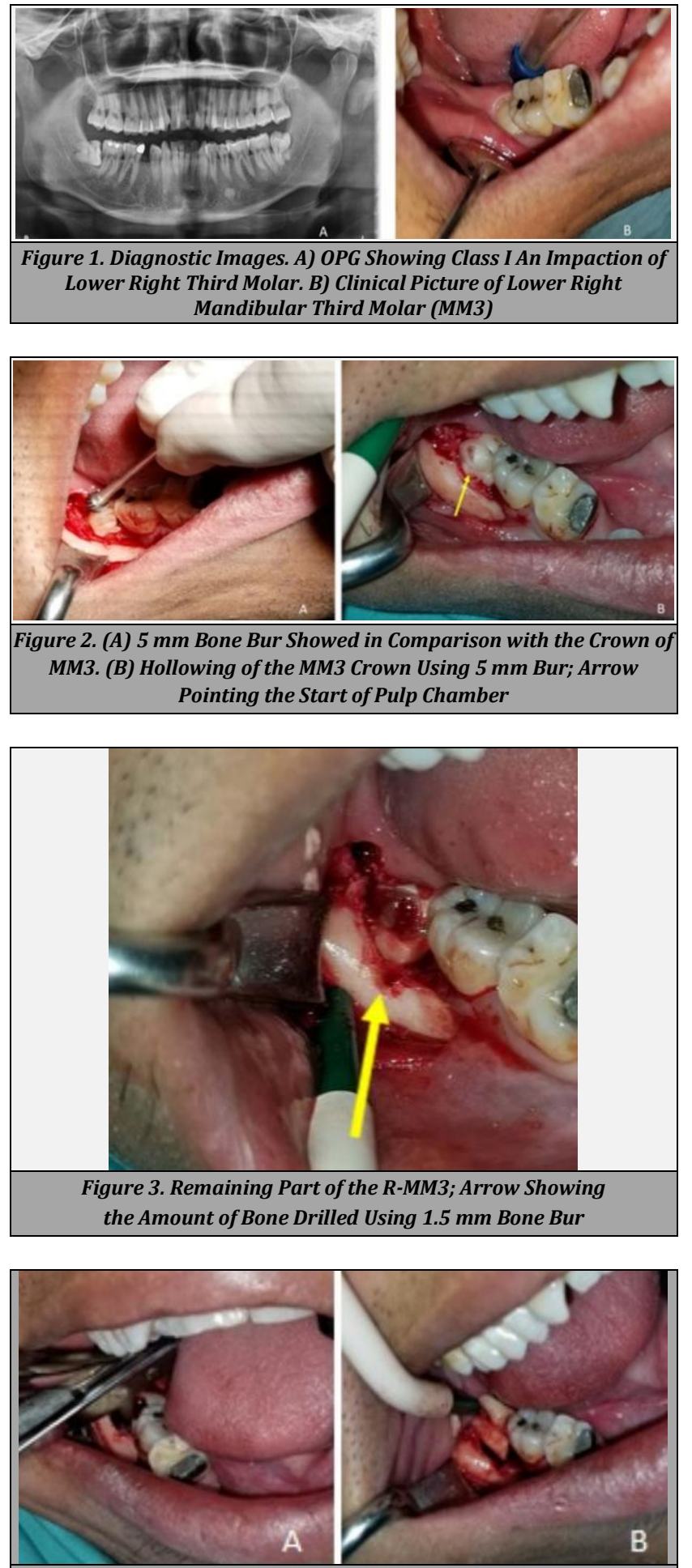

Figure 4. (A) Implosion of Buccal and Lingual Walls of R-MM3 Using a Lower Root Forceps. (B) The Roots Elevated and Held at the Opening of the Socket

\section{CONCLUSIONS}

Implosion technique used for mandibular third molar is precise with less bone removal and less surgical time when compared with the conventional methods. Implosion technique showed least amount of discomfort and postoperative complications. 7 out of 10 patients reported with no pain on third day post-surgery. 
Financial or other competing interests: None.

Disclosure forms provided by the authors are available with the full text of this article at jemds.com.

\section{REFERENCES}

[1] Flygare L, Öhman A. Preoperative imaging procedures for lower wisdom teeth removal. Clin Oral Investig 2008;12(4):291-302.

[2] Singh V, Alex K, Pradhan R, et al. Techniques in the removal of impacted mandibular third molar: a comparative study. European J Gen Dent 2013;2(1):2530 .
[3] Contar CMM, de Oliveira $\mathrm{P}$, Kanegusuku $\mathrm{K}$, et al. Complications in third molar removal: a retrospective study of 588 patients. Med Oral Patol Oral Cir Bucal 2010;15(1):e74-8.

[4] Alvira-González J, Figueiredo R, Valmaseda-Castellón E, et al. Predictive factors of difficulty in lower third molar extraction: a prospective cohort study. Med Oral Patol Oral Cir Bucal 2017;22(1):e108-e14.

[5] Sortino F, Pedullà E, Masoli V. The piezoelectric and rotatory osteotomy technique in impacted third molar surgery: comparison of postoperative recovery. J Oral Maxillofac Surg 2008;66(12):2444-8. 